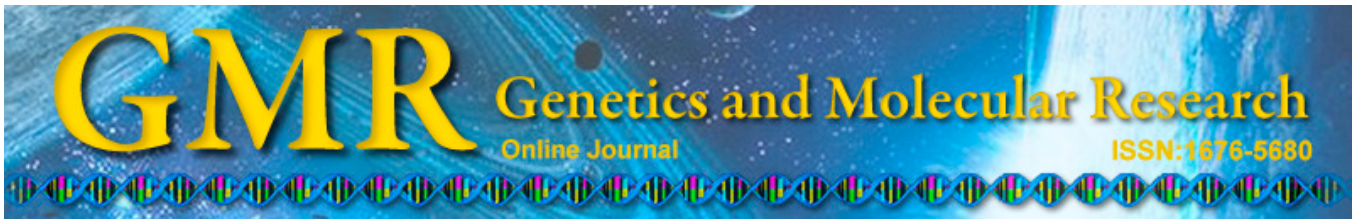

\title{
Effects of abnormal optineurin expression on the survival of the rat retinal ganglion cell line RGC-5
}

\author{
Z.R. Xu ${ }^{1,2}$, F.G. Jiang ${ }^{2}$ and F. Chen ${ }^{2}$ \\ ${ }^{1}$ Ophthalmology Department, People's Hospital, Nanshan District, \\ Shenzhen, Guangdong, China \\ ${ }^{2}$ Ophthalmology Department, Affiliated Union Hospital, \\ Tongji Medical College, Huazhong University of Science and Technology, \\ Wuhan, Hubei, China \\ Corresponding author: F. Chen \\ E-mail: chenfai_cf@163.com
}

Genet. Mol. Res. 14 (3): 9171-9180 (2015)

Received January 9, 2015

Accepted May 29, 2015

Published August 7, 2015

DOI http://dx.doi.org/10.4238/2015.August.7.27

\begin{abstract}
The OPTN gene is thought to be associated with certain types of glaucoma and the function of the protein for which it encodes, optineurin, has been extensively researched, but with contradictory results. We explored the effects of abnormal optineurin expression on the survival of the rat retinal ganglion cell line RGC-5. Plasmids expressing wild-type (WT) or E50K mutant optineurin, or OPTN-specific doublehairpin small interfering RNA (si-RNA), were transfected into RGC-5 cells. The effects on cell survival were monitored by observation of cell morphology and propidium iodide and Hoechst 33342 fluorescent staining, while expression of optineurin was visualized by fluorescence microscopy. Abnormal optineurin expression influenced the survival of RGCs in vitro, as apoptosis was induced by increased WT and E50K mutant optineurin, while a reduction in apoptosis was observed in cells transfected with OPTN-siRNA. Similar results were also observed in transfected cells treated with apoptotic stimuli. Overexpression
\end{abstract}


of WT and mutant E50K protein resulted in greater cell death, while downregulation decreased RGC-5 apoptosis.

Key words: OPTN; RGC-5; Cell survival; Apoptotic stimulus

\section{INTRODUCTION}

Glaucoma is the second leading cause of permanent blindness worldwide and is characterized by a gradual loss of vision resulting from the death of retinal ganglion cells (RGCs; Quigley, 1996). It has been suggested that a number of genetic susceptibility factors contribute to glaucoma (Wolfs et al., 1998). OPTN, which codes for the protein optineurin, has been implicated in normal-tension glaucoma (NTG) and primary open angle glaucoma (POAG; Rezaie et al., 2002; Sarfarazi and Rezaie, 2003). Optineurin is a cytoplasmic protein and is preferentially expressed in RGCs. Consisting of 577 amino acids, it has been reported to interact with several proteins of diverse functions, such as transcription factor IIIA (Moreland et al., 2000), myosin VI (Sahlender et al., 2005), Rab8 (Chibalina et al., 2008), huntingtin (del Toro et al., 2009), metabotropic glutamate receptor (Anborgh et al., 2005), TANK protein kinase (Morton et al., 2008), and adenovirus E3 14.7-kDa protein (Li et al., 1998). The role of optineurin in cell survival has been studied extensively, but with contradictory results. For example, De Marco et al. (2006) found that following an apoptotic stimulus, optineurin functions to increase cell survival. This is in contrast to the results obtained by Park et al. (2006), who found that overexpression of wild-type (WT) optineurin increases cell death. Some researchers have suggested that this effect may be related to cell type (Park et al., 2006) or the baseline optineurin expression of the cells under study (Chalasani et al., 2007). As this protein is highly expressed in RGCs, the rat retinal ganglion cell line RGC-5 was used to investigate the effects of its abnormal expression on cell survival.

In this study, we modified the expression of optineurin by transfecting cells with plasmids expressing the WT protein and the E50K mutant, the most common pathogenic mutation of this protein, in which glutamic acid at position 50 is replaced by lysine in the translated sequence (Sarfarazi et al., 1998; Rezaie et al., 2002; Sarfarazi and Rezaie, 2003). In other cells, $O P T N$-specific double-hairpin small interfering RNA (siRNA) was expressed. Our aim was to explore the effects of optineurin on cell survival in the rat retinal ganglion cell line RGC-5.

\section{MATERIAL AND METHODS}

\section{Expression plasmids}

The coding region of rat OPTN complementary DNA (cDNA) was amplified by polymerase chain reaction (PCR) using a placental cDNA library as the template. The nucleotide sequence of the cloned gene was identical to that reported in the RefSeq database (accession No. NM_145081). The PCR product was cloned in a pEGFP-N1 vector. Mutations in OPTN cDNA were created using a PCR-based, site-directed mutagenesis strategy to make the E50K mutant. Nucleotide sequences of mutant and WT cDNA constructs were confirmed by automated DNA sequencing, while protein expression was confirmed by fluorescence microscopy analysis of transfected cells. Expression plasmids for $O P T N$-specific double-hairpin siRNA were screened and validated using western blotting and real-time PCR. 
Hoechst 33342 stain and propidium iodide (PI) were obtained from Sigma (St. Louis, MO, USA). Cell culture reagents were obtained from GE Healthcare (Waukesha, WI, USA; HyClone culture medium and fetal bovine serum) or Amresco (Solon, OH, USA; phosphate-buffered saline and trypsin solution).

\section{Cell culture, transfections, and fluorescence imaging}

RGC-5 cells were grown as monolayers in Dulbecco's modified Eagle's medium containing $5 \%$ fetal calf serum in a humidified $37^{\circ} \mathrm{C}$ incubator in $5 \% \mathrm{CO}_{2}$. Transient transfections were performed using column-purified plasmids (Qiagen, Valencia, CA, USA) and Lipofectamine 2000 reagent (Invitrogen, Carlsbad, CA, USA), according to the manufacturer protocol. For fluorescence imaging, RGC-5 cells were grown on coverslips and transfected with the required plasmids prior to being visualized.

\section{Cell death assays}

Quantitative analysis of dead or apoptotic cells was carried out as follows. Cells grown on coverslips were transfected with $250 \mathrm{ng}$ plasmids expressing WT optineurin, the E50K mutant, or OPTN-specific si-RNA and were stained with Hoechst 33342 and PI at 24, 48 , and $96 \mathrm{~h}$ after transfection.

\section{$\mathrm{H}_{2} \mathrm{O}_{2}$ and glutamate-induced cell death assays}

Cells grown on coverslips were transfected with 250 ng plasmids expressing WT optineurin, the E50K mutant, or OPTN-specific si-RNA. At $24 \mathrm{~h}$ after transfection, the cells were treated with $\mathrm{H}_{2} \mathrm{O}_{2}(650 \mu \mathrm{M})$ or glutamate $(10 \mathrm{mM})$ for $1 \mathrm{~h}$, before being fixed and stained with Hoechst 33342 and PI. The percentage of dead cells was quantified by determining the proportion of those stained with PI to those stained with Hoechst 33342.

\section{Statistical analysis}

Data are reported as means \pm standard deviations. Statistical comparisons were performed using one-way ANOVA followed by the Student-Newman-Keuls $q$-test using SPSS version 13.0 (SPSS Inc., Chicago, IL, USA), or the chi-square test. P values lower than 0.05 were considered to be statistically significant.

\section{RESULTS}

As the death of RGCs constitutes the primary pathological process in glaucoma, we used a useful model of these cells derived from rats, RGC-5 (Krishnamoorthy et al., 2001), to analyze the effect of abnormal optineurin expression on cell survival. RGC-5 cells grown on coverslips were transfected with plasmids expressing WT optineurin, the E50K mutant, or $O P T N$-specific si-RNA. Transfected cells were then stained with Hoechst 33342 and PI and examined by fluorescence microscopy.

Using fluorescence microscopy, transfection efficiency was found to be $17.43 \pm 0.94$, $20.13 \pm 1.24$, and $19.37 \pm 0.54 \%$ at 24,48 , and $96 \mathrm{~h}$ after transfection, respectively. While 
cells in the blank $(0.74 \pm 0.34 \%)$ and negative $(0.96 \pm 0.41 \%)$ control groups appeared normal, apoptosis was observed in the positive control, WT, E50K, and OPTN-siRNA groups $24 \mathrm{~h}$ after transfection $(\mathrm{P}<0.05)$, as revealed by the loss of refractility, condensation of chromatin, and decrease in cell size caused by shrinkage of the cytoplasm (Figure 1). However, in the $O P T N$-siRNA group, the level of apoptosis was lower than that in the positive control group $(\mathrm{P}<0.05)$. The rate of apoptosis increased with the length of time since transfection, i.e., it was higher at $48 \mathrm{~h}$ than at $24 \mathrm{~h}$, with the exception of the positive control. After $96 \mathrm{~h}$, apoptosis was observed in the positive control and $O P T N$-siRNA groups, but to a lesser extent than that observed in the 48-h cultures. However, the rate of apoptosis was seen to increase further in the WT optineurin and E50K groups (Table 1 and Figure 2).

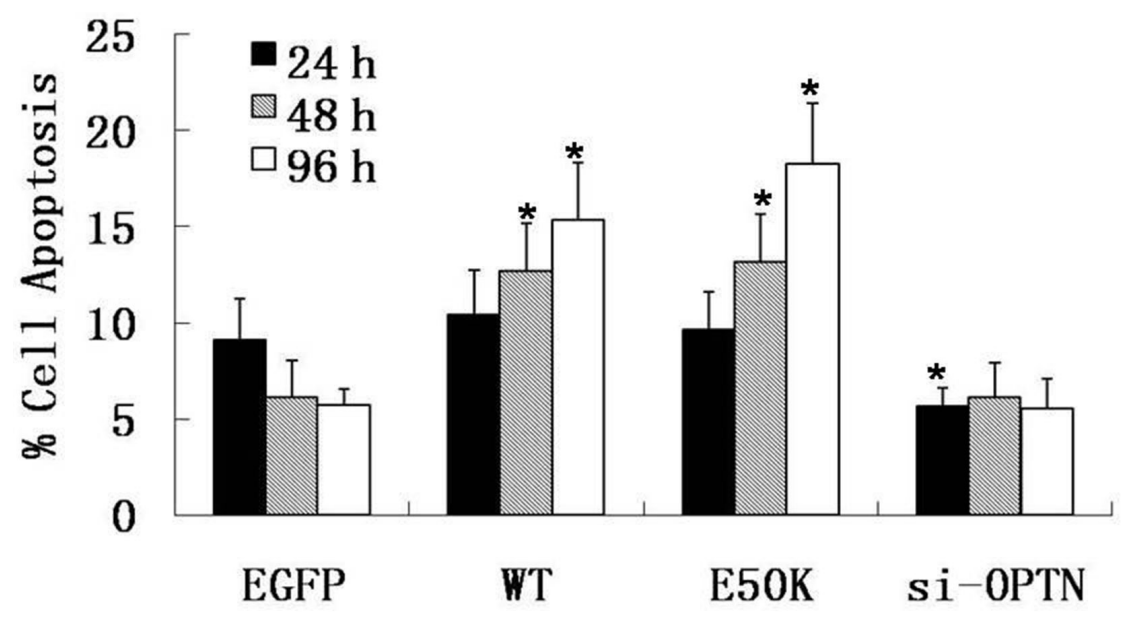

Figure 1. Apoptosis of RGC-5 cells expressing the empty EGFP vector, wild-type (WT) optineurin, E50K mutant optineurin, or $O P T N$-siRNA. $* \mathrm{P}<0.05$ vs positive control at the same time point.

Table 1. Apoptosis of RGC-5 cells expressing the empty EGFP vector, wild-type (WT) optineurin, E50K mutant optineurin, or $O P T N$-siRNA.

\begin{tabular}{|c|c|c|c|}
\hline \multirow[t]{2}{*}{ Group } & \multicolumn{3}{|c|}{ Apoptosis (\%) } \\
\hline & $24 \mathrm{~h}$ & $48 \mathrm{~h}$ & $96 \mathrm{~h}$ \\
\hline EGFP & $9.09 \pm 2.17$ & $6.11 \pm 1.94$ & $5.69 \pm 0.83$ \\
\hline WT OPTN & $10.42 \pm 2.31$ & $10.71 \pm 2.44^{*}$ & $15.38 \pm 2.92^{*}$ \\
\hline E50K OPTN & $9.62 \pm 1.96$ & $13.19 \pm 2.45^{*}$ & $18.26 \pm 3.17^{*}$ \\
\hline$O P T N$-siRNA & $5.66 \pm 0.94 *$ & $6.06 \pm 1.83$ & $5.56 \pm 1.53$ \\
\hline
\end{tabular}

$* \mathrm{P}<0.05$ vs positive control at the same time point.

To further investigate the survival of RGCs expressing abnormal optineurin, we treated transfected cells with $10 \mathrm{mM}$ glutamate. Hoechst 33342 and PI staining showed that apoptosis in the four groups had clearly increased $24 \mathrm{~h}$ following transfection. As the time since transfection was extended to $48 \mathrm{~h}$, the apoptosis rate continued to increase, with the exception of the positive control group and those cells expressing $O P T N$-siRNA. The level of apoptosis in all four groups was higher after $96 \mathrm{~h}$ than after $48 \mathrm{~h}(\mathrm{P}<0.05$; Table 2, Figures 3 and 4). 


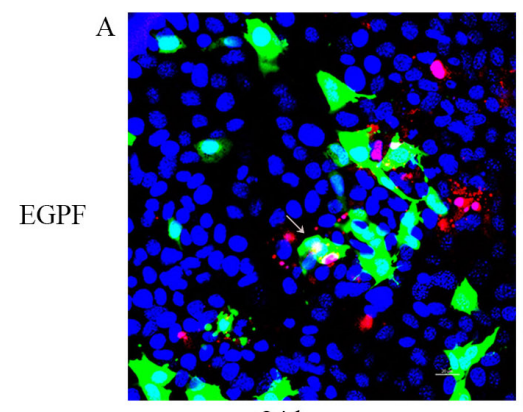

$24 \mathrm{~h}$

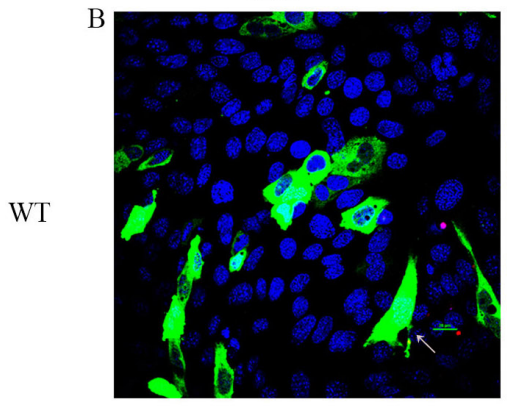

$24 \mathrm{~h}$

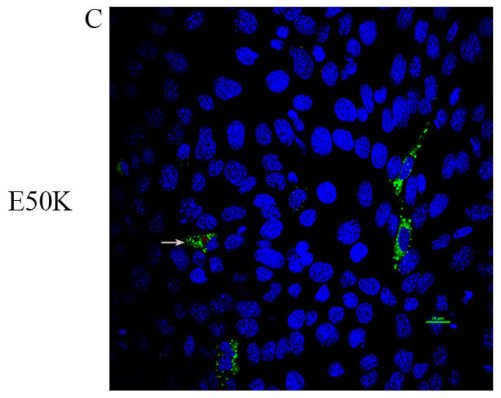

$24 \mathrm{~h}$

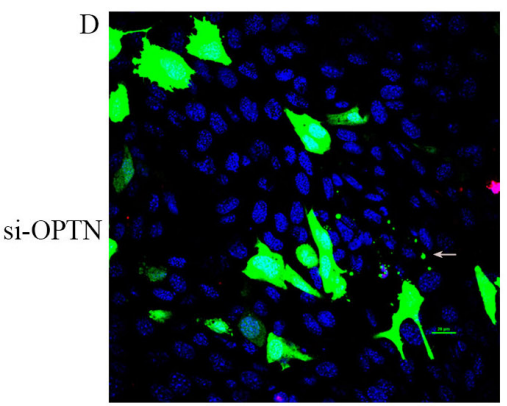

$24 \mathrm{~h}$

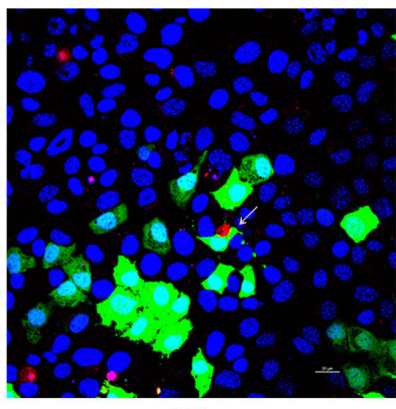

$48 \mathrm{~h}$

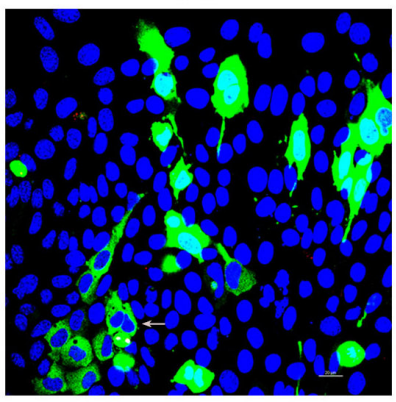

$48 \mathrm{~h}$

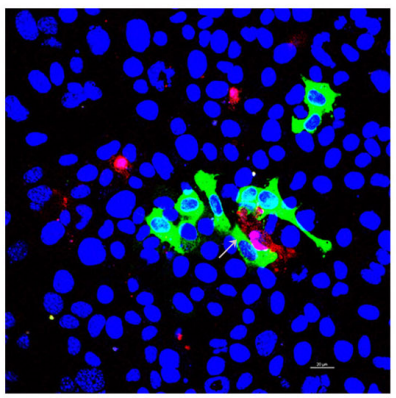

$48 \mathrm{~h}$

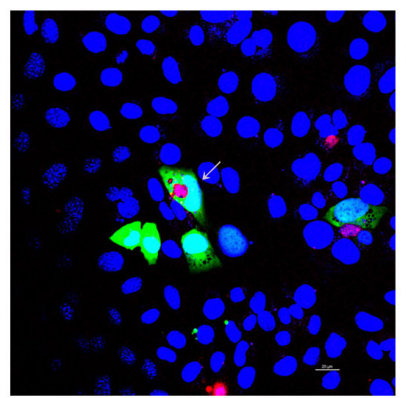

$48 \mathrm{~h}$

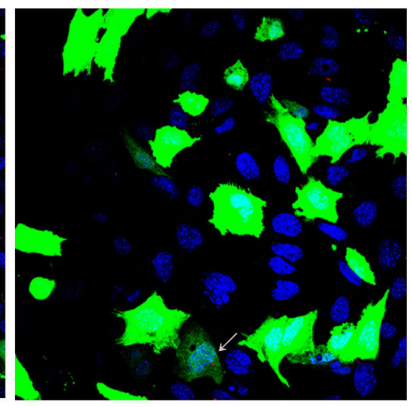

$96 \mathrm{~h}$

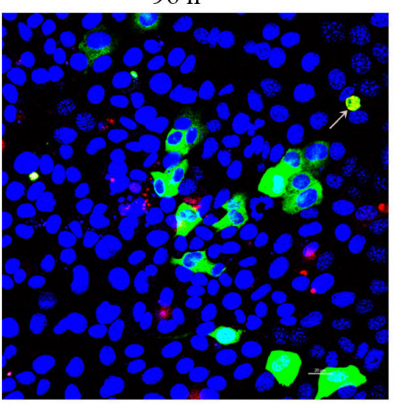

$96 \mathrm{~h}$

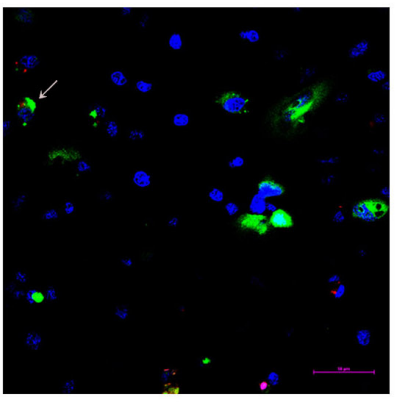

$96 \mathrm{~h}$

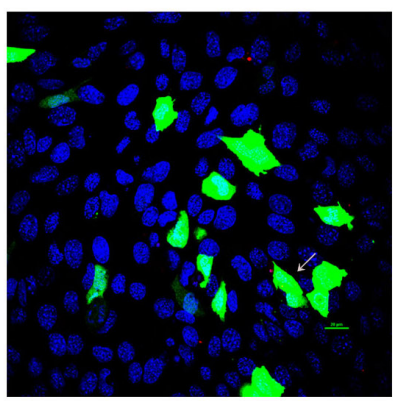

$96 \mathrm{~h}$

Figure 2. Laser confocal imaging of RGC-5 cells expressing the empty EGFP vector (A), wild-type (WT) optineurin (B), E50K mutant optineurin (C), or OPTN-siRNA (D) (transfected cells are seen in green) and stained with Hoechst 33342 (blue) and propidium iodide (red) in cells at 24, 48, and $96 \mathrm{~h}$ after transfection. Arrowheads indicate apoptotic and necrotic cells. 
Table 2. Apoptosis of RGC-5 cells expressing the empty EGFP vector, wild-type (WT) optineurin, E50K mutant optineurin, or $O P T N$-siRNA and treated with glutamate for $1 \mathrm{~h}$.

\begin{tabular}{|c|c|c|c|}
\hline \multirow[t]{2}{*}{ Group } & \multicolumn{3}{|c|}{ Apoptosis (\%) } \\
\hline & $24 \mathrm{~h}$ & $48 \mathrm{~h}$ & $96 \mathrm{~h}$ \\
\hline EGFP & $10.34 \pm 3.04$ & $6.41 \pm 1.23$ & $7.89 \pm 0.98$ \\
\hline WT OPTN & $15.25 \pm 2.39^{*}$ & $20.31 \pm 2.51 *$ & $21.43 \pm 4.93 *$ \\
\hline E50K OPTN & $17.24 \pm 5.37^{*}$ & $20.48 \pm 2.63 *$ & $23.21 \pm 2.84 *$ \\
\hline$O P T N$-siRNA & $11.54 \pm 3.36$ & $5.74 \pm 1.35$ & $7.58 \pm 1.54$ \\
\hline
\end{tabular}

$* \mathrm{P}<0.05$ vs positive control at the same time point.

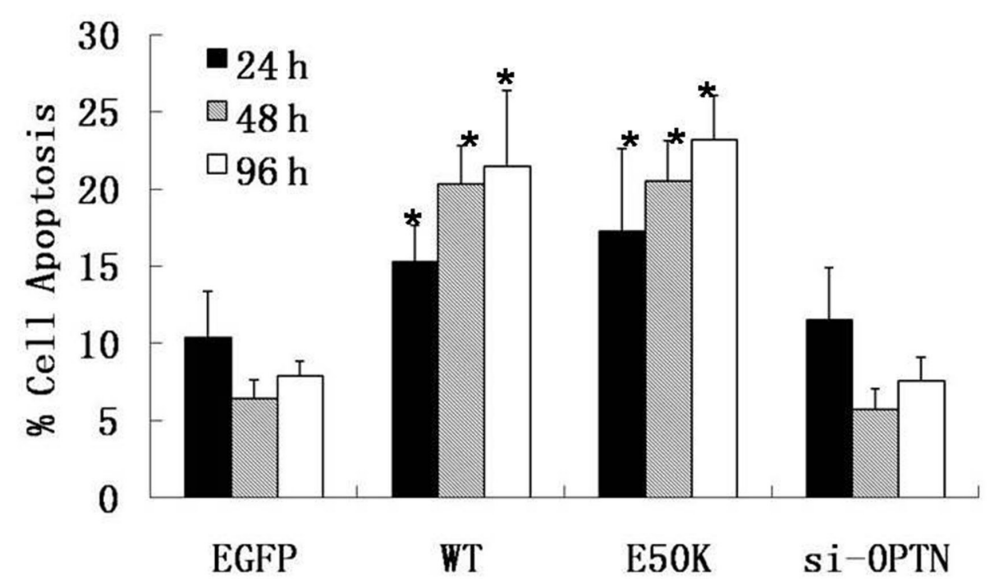

Figure 3. Apoptosis of RGC-5 cells expressing the empty EGFP vector, wild-type (WT) optineurin, E50K mutant optineurin, or $O P T N$-siRNA and treated with glutamate for $1 \mathrm{~h}$. $* \mathrm{P}<0.05 v s$ positive control at the same time point.

Cells were also treated with $650 \mu \mathrm{M} \mathrm{H}_{2} \mathrm{O}_{2}$. Compared to the negative control group $(17.33 \pm 4.13 \%)$, apoptosis was observed in the positive control, WT, E50K, and OPTNsiRNA groups $24 \mathrm{~h}$ after transfection $(\mathrm{P}<0.05)$. However, the apoptosis rate in all four groups had decreased after $48 \mathrm{~h}$. After $96 \mathrm{~h}$, this rate had further decreased, with the exception of the E50K and WT optineurin groups $(\mathrm{P}<0.05$; Table 3, Figures 5 and 6$)$.

\section{DISCUSSION}

Glaucoma is a disease causing permanent blindness and has been shown to have a hereditary component (Wolfs et al., 1998). One of the genes implicated in NTG and POAG is OPTN. However, little is known about the molecular mechanisms behind optineurin-associated glaucoma pathogenesis. Abnormal expression of optineurin may be associated with the onset of glaucoma, but results regarding its effect on cell survival contradict each other, possibly due to the use of different cell types or cellular baseline optineurin expression (De Marco et al., 2006; Park et al., 2006; Chalasani et al., 2007). Regardless of its pathogenesis, injury to and death of RGCs constitute the final stage of glaucoma. RGCs are the cells most affected during POAG, and the key to demonstrating the role of optineurin in the onset of this disease is the investigation of its effect on RGC survival. 


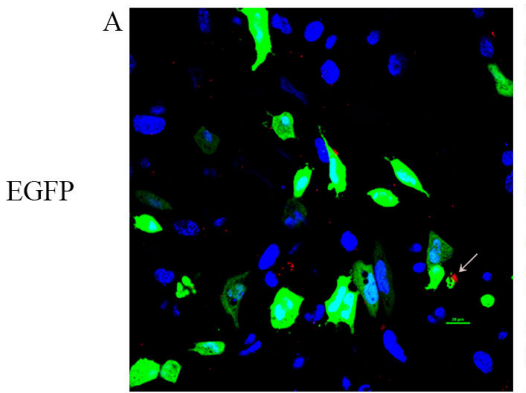

$24 \mathrm{~h}$

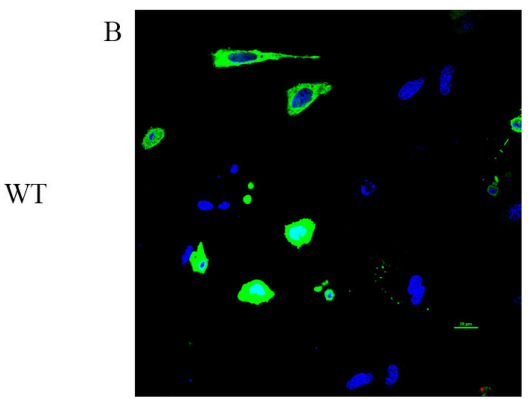

$24 \mathrm{~h}$

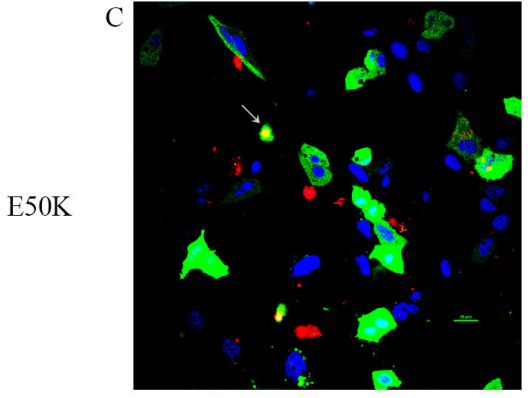

$24 \mathrm{~h}$

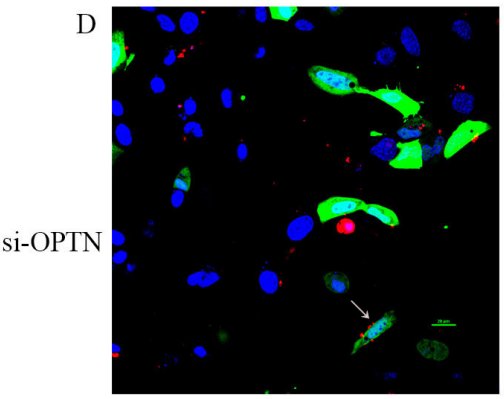

$24 \mathrm{~h}$

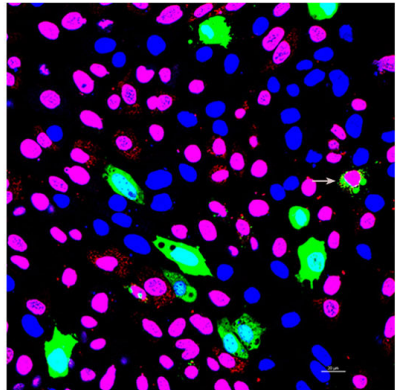

$48 \mathrm{~h}$

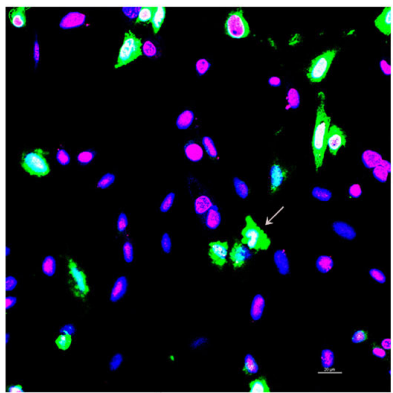

$48 \mathrm{~h}$

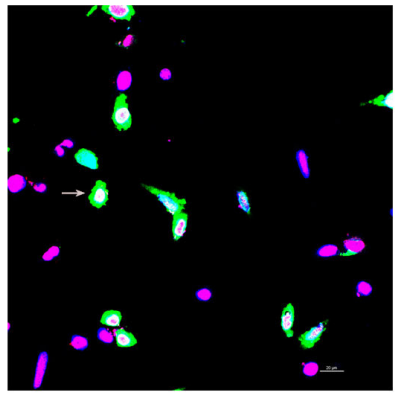

$48 \mathrm{~h}$

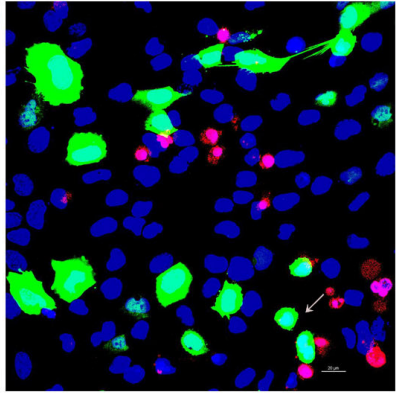

$48 \mathrm{~h}$

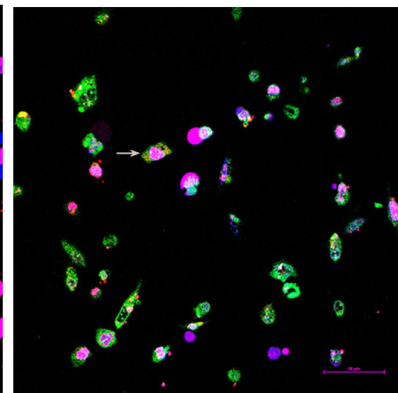

$96 \mathrm{~h}$

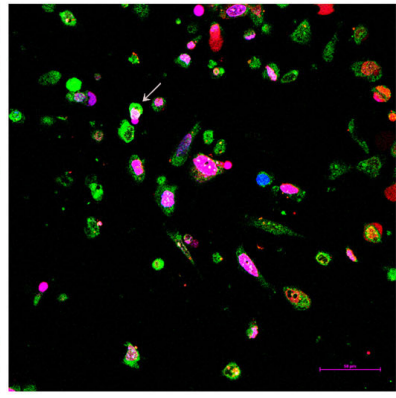

$96 \mathrm{~h}$

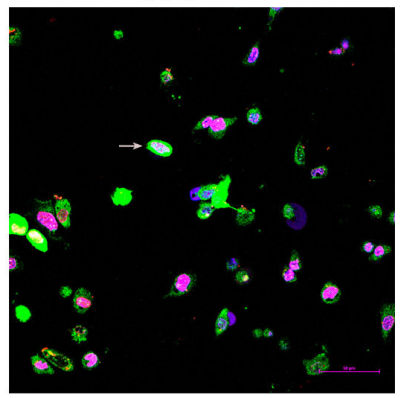

$96 \mathrm{~h}$

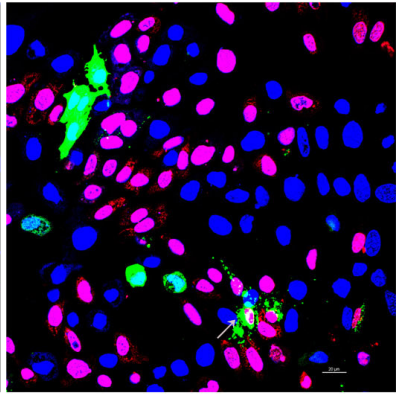

$96 \mathrm{~h}$

Figure 4. Laser confocal imaging of RGC-5 cells expressing the empty EGFP vector (A), wild-type (WT) optineurin (B), E50K mutant optineurin (C), or OPTN-siRNA (D) (transfected cells are seen in green) and stained with Hoechst 33342 (blue) and propidium iodide (red) $1 \mathrm{~h}$ after glutamate treatment in cells at 24, 48, and $96 \mathrm{~h}$ after transfection. Arrowheads indicate apoptotic and necrotic cells. Apoptosis was observed in all groups following glutamate treatment. 
Table 3. Apoptosis of RGC-5 cells expressing the empty EGFP vector, wild-type (WT) optineurin, E50K mutant optineurin, or $O P T N$-siRNA and treated with $\mathrm{H}_{2} \mathrm{O}_{2}$ for $1 \mathrm{~h}$.

\begin{tabular}{lccc}
\hline Group & \multicolumn{3}{c}{ Apoptosis (\%) } \\
\cline { 2 - 4 } & $24 \mathrm{~h}$ & $48 \mathrm{~h}$ & $96 \mathrm{~h}$ \\
\hline EGFP & $26.42 \pm 7.63$ & $11.67 \pm 2.81$ & $9.09 \pm 1.53$ \\
WT OPTN & $22.22 \pm 7.94^{*}$ & $9.52 \pm 1.38^{*}$ & $25.03 \pm 4.06^{*}$ \\
E50K OPTN & $36.28 \pm 8.03^{*}$ & $10.81 \pm 1.92$ & $28.37 \pm 4.32^{*}$ \\
OPTN-siRNA & $19.21 \pm 6.37^{*}$ & $10.11 \pm 2.04$ & $7.36 \pm 0.49$ \\
\hline
\end{tabular}

$* \mathrm{P}<0.05 v s$ positive control at the same time point.

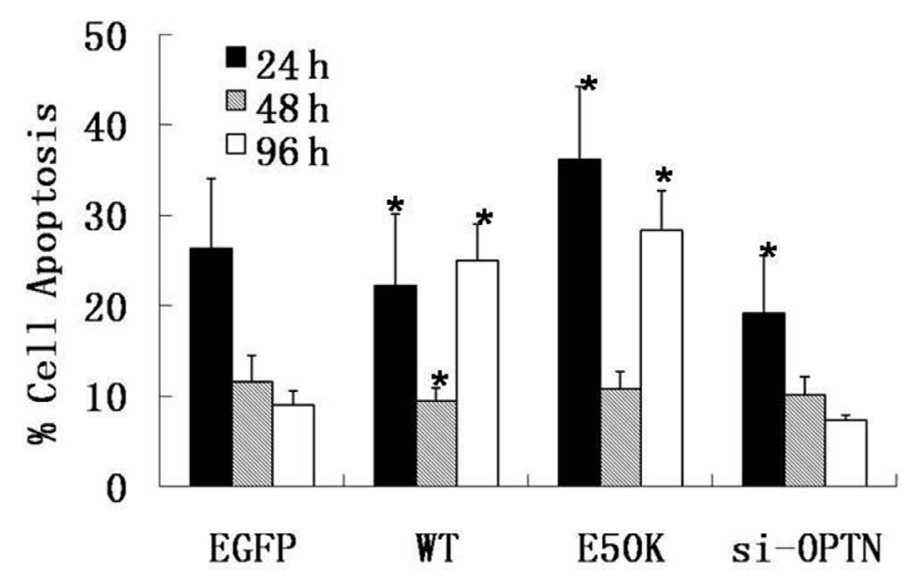

Figure 5. Apoptosis of RGC-5 cells expressing the empty EGFP vector, wild-type (WT) optineurin, E50K mutant optineurin, or $O P T N$-siRNA and treated with $\mathrm{H}_{2} \mathrm{O}_{2}$ for $1 \mathrm{~h}$. ${ }^{*} \mathrm{P}<0.05$ vs positive control at the same time point.

Our results show that the degree of RGC apoptosis observed in the positive control, WT, and E50K groups increased $24 \mathrm{~h}$ after transfection $(\mathrm{P}<0.05)$ compared to the blank $(0.74$ $\pm 0.34 \%)$ and negative $(0.96 \pm 0.41 \%)$ control groups. This is consistent with the results of Chalasani et al. (2007), whose report suggested that the ability of WT optineurin and the E50K mutant form to induce cell death appears to be specific to RGCs. Neither this mutant nor WT optineurin was able to induce cell death in IMR-32 (a neuronal cell line), HeLa, or COS-1 cells; differing levels of endogenous optineurin may be responsible for this phenomenon. In addition, our study shows that the effect of this protein on RGC survival was time-dependent.

Using siRNA techniques, a previous study (Rezaie and Sarfarazi, 2005) showed that downregulation of optineurin altered the morphology of the Golgi complex in normal rat kidney and HeLa cells, and increased cell apoptosis. In our investigation on RGCs, however, we found that suppression of optineurin had a cytoprotective effect in comparison to the positive control group. This discrepancy may be caused by differing baseline levels of endogenous optineurin in different cell lines.

Changes in the extent of RGC apoptosis following $\mathrm{H}_{2} \mathrm{O}_{2}$ or glutamate treatment were observed, with higher and fluctuating levels in transfected cells following an apoptotic stimulus, possibly related to the NF- $\kappa B$ pathway. Optineurin translocates to the nucleus after $\mathrm{H}_{2} \mathrm{O}_{2}$ stimulation, which reduces the negative regulatory effect it has on the NF- $\mathrm{KB}$ pathway. Thus, 


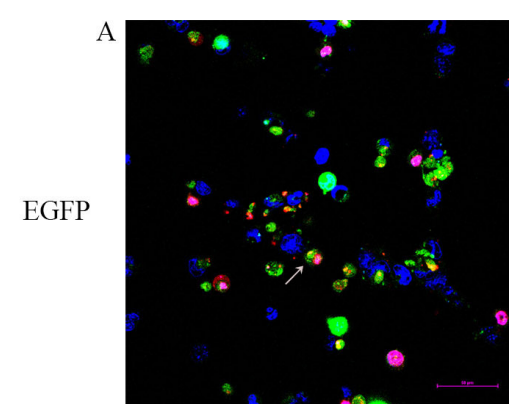

$24 \mathrm{~h}$

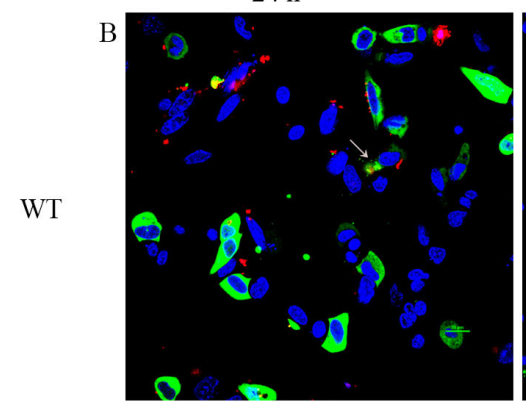

$24 \mathrm{~h}$

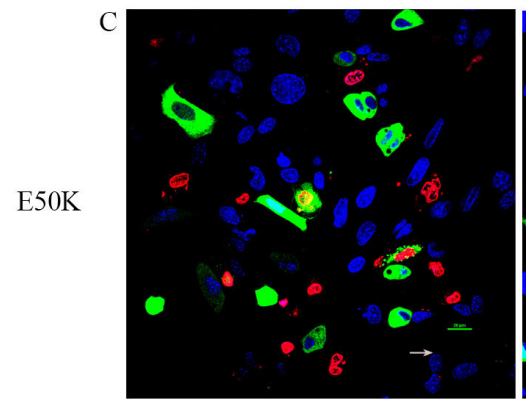

$24 \mathrm{~h}$

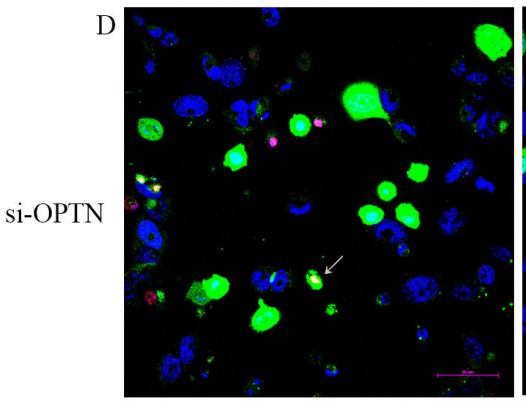

$24 \mathrm{~h}$

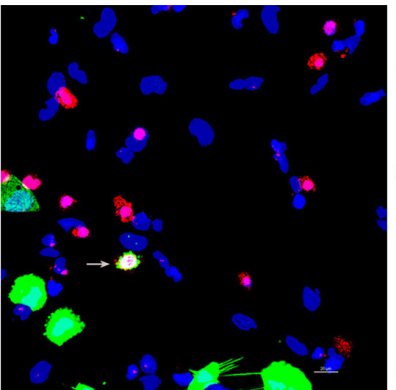

$48 \mathrm{~h}$

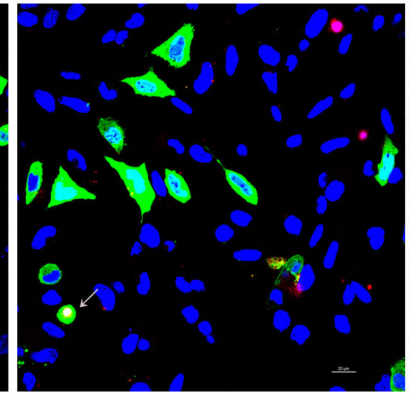

$48 \mathrm{~h}$

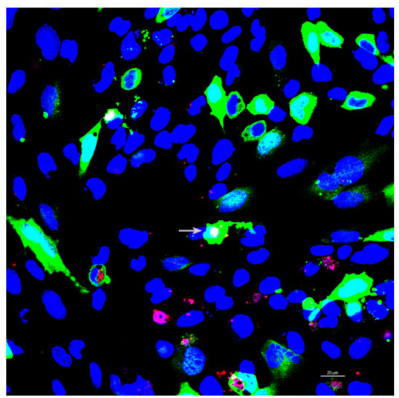

$48 \mathrm{~h}$

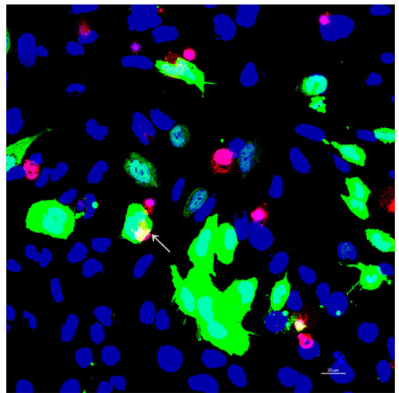

$48 \mathrm{~h}$

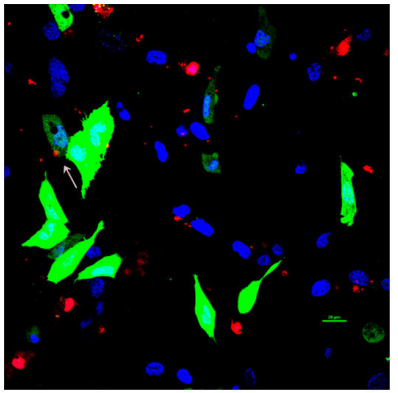

$96 \mathrm{~h}$

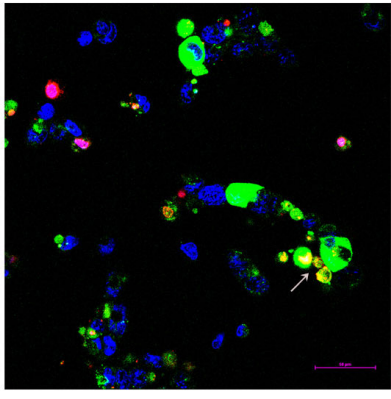

$96 \mathrm{~h}$

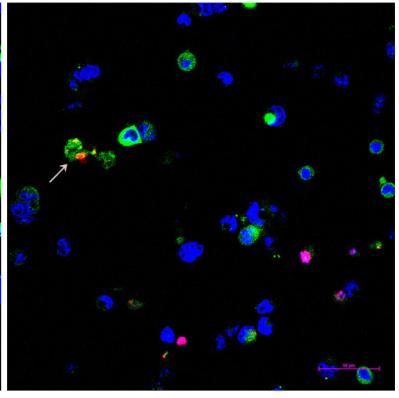

$96 \mathrm{~h}$

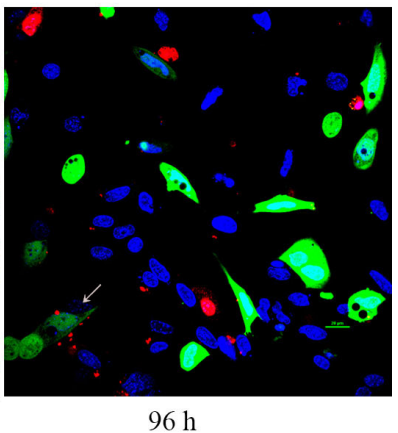

Figure 6. Laser confocal imaging of RGC-5 cells expressing the empty EGFP vector (A), wild-type (WT) optineurin (B), E50K mutant optineurin (C), or OPTN-siRNA (D) (transfected cells are seen in green) and stained with Hoechst 33342 (blue) and propidium iodide (red) $1 \mathrm{~h}$ after $\mathrm{H}_{2} \mathrm{O}_{2}$ treatment in cells at 24, 48, and $96 \mathrm{~h}$ after transfection. Arrowheads indicate apoptotic and necrotic cells. Apoptosis was observed in all groups following $\mathrm{H}_{2} \mathrm{O}_{2}$ treatment. 
heightened expression of NF- $\mathrm{kB}$ increases resistance to apoptosis (De Marco et al., 2006). However, NF- $\kappa \mathrm{B}$ expression increases that of optineurin, overexpression of which, combined with apoptotic stress, leads to rapid inactivation of NF-אB (Sudhakar et al., 2009).

Our study shows that overexpression of optineurin, both WT and the E50K mutant form, had a pathological effect, while its suppression afforded a degree of cytoprotection. These results may be related to oxidative stress and vesicle trafficking activities, but the exact mechanism requires further exploration.

\section{Conflicts of interest}

The authors declare no conflict of interest.

\section{ACKNOWLEDGMENTS}

Research supported by the National Natural Science Foundation of China (\#30700922).

\section{REFERENCES}

Anborgh PH, Godin C, Pampillo M, Dhami GK, et al. (2005). Inhibition of metabotropic glutamate receptor signaling by the huntingtin binding protein optineurin. J. Biol. Chem. 280: 34840-34848.

Chalasani ML, Radha V, Gupta V, Agarwal N, et al. (2007). A glaucoma-associated mutant of optineurin selectively induces death of retinal ganglion cells which is inhibited by antioxidants. Invest. Ophthalmol. Vis. Sci. 48: 1607-1614.

Chibalina MV, Roberts RC, Arden SD, Kendrick-Jones J, et al. (2008). Rab8-optineurin-myosin VI: analysis of interactions and functions in the secretory pathway. Methods Enzymol. 438: 11-24.

De Marco N, Buono M, Troise F and Diez-Roux G (2006). Optineurin increases cell survival and translocates to the nucleus in a Rab8-dependent manner upon an apoptotic stimulus. J. Biol. Chem. 281: 16147-16156.

del Toro D, Alberch J, Lázaro-Diéguez F, Martín-Ibáñez R, et al. (2009). Mutant huntingtin impairs post-Golgi trafficking to lysosomes by delocalizing optineurin/Rab8 complex from the Golgi apparatus. Mol. Biol. Cell 20: 1478-1492.

Krishnamoorthy RR, Agarwal P, Prasanna G, Vopat K, et al. (2001). Characterization of a transformed rat ganglion cell line. Brain Res. Mol. Brain Res. 86: 1-12.

Li YG, Kang J and Horwitz MS (1998). Interaction of an adenovirus E3 14.7-kilodalton protein with a novel tumor necrosis factor alpha-inducible cellular protein containing leucine zipper domains. Mol. Cell Biol. 18: 1601-1610.

Moreland RJ, Dresser ME, Rodgers JS, Roe BA, et al. (2000). Identification of a transcription factor IIIA-interacting protein. Nucleic Acids Res. 28: 1986-1993.

Morton S, Hesson L, Peggie M and Cohen P (2008). Enhanced binding of TBK1 by an optineurin mutant that causes a familial form of primary open angle glaucoma. FEBS Lett. 582: 997-1002.

Park BC, Shen X, Samaraweera M and Yue BY (2006). Studies of optineurin, a glaucoma gene: Golgi fragmentation and cell death from overexpression of wild-type and mutant optineurin in two ocular cell types. Am. J. Pathol. 169: 1976-1989.

Quigley HA (1996). Number of people with glaucoma worldwide. Br. J. Ophthalmol. 80: 389-393.

Rezaie T and Sarfarazi M (2005). Molecular cloning, genomic structure, and protein characterization of mouse optineurin. Genomics 85: 131-138.

Rezaie T, Child A, Hitchings R, Brice G, et al. (2002). Adult-onset primary open-angle glaucoma caused by mutations in optineurin. Science 295: 1077-1079.

Sahlender DA, Roberts RC, Arden SD, Spudich G, et al. (2005). Optineurin links myosin VI to the Golgi complex and is involved in Golgi organization and exocytosis. J. Cell Biol. 169: 285-295.

Sarfarazi M and Rezaie T (2003). Optineurin in primary open angle glaucoma. Ophthalmol. Clin. North Am. 16: 529-541.

Sarfarazi M, Child A, Stoilova D, Brice G, et al. (1998). Localization of the fourth locus (GLC1E) for adult-onset primary open-angle glaucoma to the 10p15-p14 region. Am. J. Hum. Genet. 62: 641-652.

Sudhakar C, Nagabhushana A, Jain N and Swarup G (2009). NF-kappaB mediates tumor necrosis factor alpha-induced expression of optineurin, a negative regulator of NF-kappaB. PLoS One 4: e5114.

Wolfs RC, Klaver CC, Ramrattan RS, van Duijn CM, et al. (1998). Genetic risk of primary open-angle glaucoma. Population-based familial aggregation study. Arch. Ophthalmol. 116: 1640-1645. 